\title{
10 | Las patentes de hormigón armado. Del gran negocio al gran desarrollo tecnológico. Los antecedentes del Movimiento Moderno
} _Armando Valenzuela

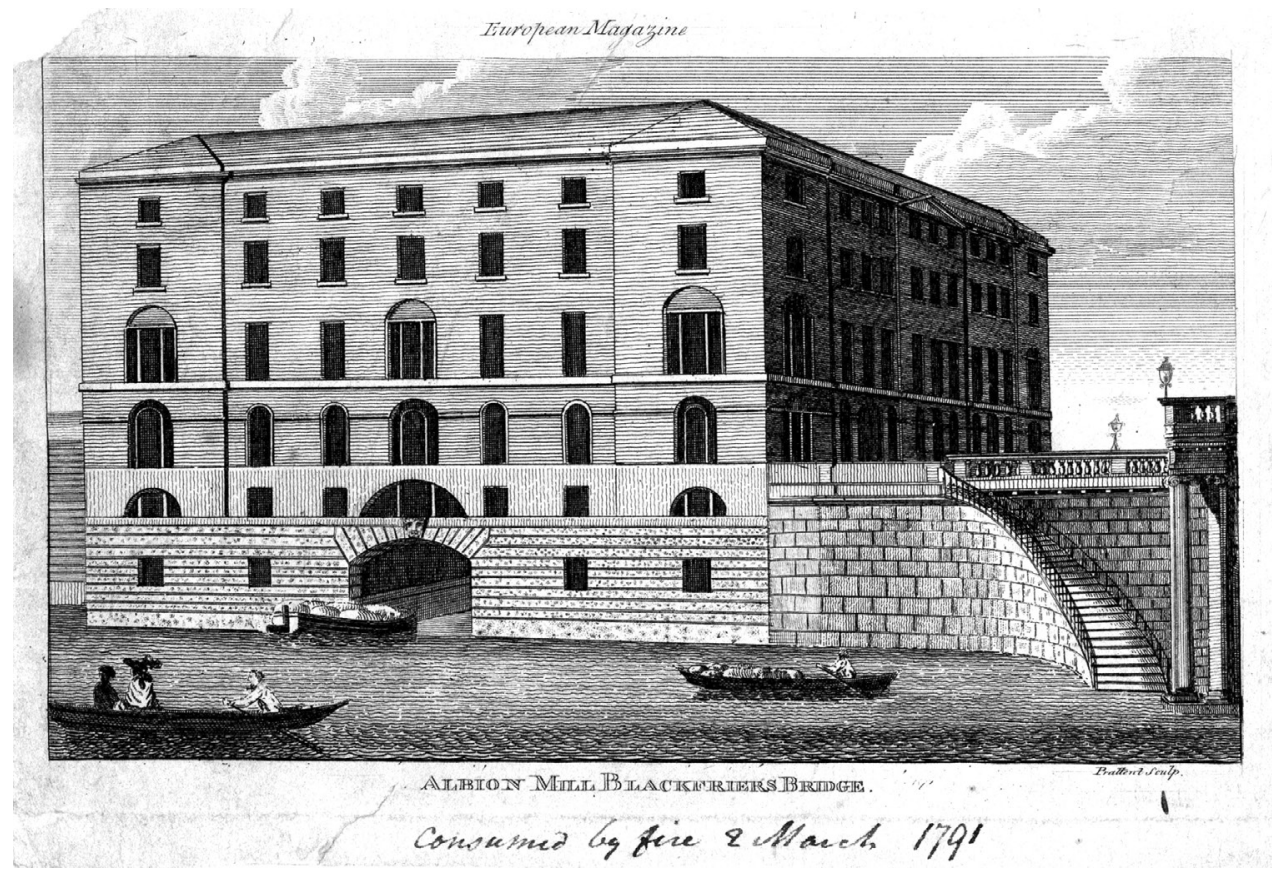

[1]

\section{Resumen pág 57 | Bibliografía pág 62}

Armando Valenzuela es arquitecto desde 1997. Actividad profesional de forma independiente desde 1998 (Orv arquitectos S.L.). Doctorando por el Departamento de Composición de la ETSAM; Conferenciante en 2013 en la ETSAM: Owen Williams, la arquitectura de un ingeniero. Profesor invitado desde 2008 en los seminarios de verano de la Universidad de Paris-Est Créteil dentro del Máster para estudiantes universitarios latinoamericanos sobre Políticas urbanas y edificios destinados a actividades juveniles.

\section{Palabras clave}

Patente, hormigón, fungiforme, Hennebique, Monier, Ransome

\section{Introducción}

El desarrollo de la Arquitectura del siglo XX, y especialmente la arquitectura Moderna, no puede entenderse desasociado de la evolución de las tecnologías de la construcción y los sistemas estructurales. La revolución industrial, sobre todo el segundo período -el comprendido entre 18401870 y principios del siglo $\mathrm{XX}$ - fue un tiempo de grandes avances tecnológicos y enormes cambios sociales que tuvieron su reflejo en la configuración de las ciudades y los modos de producción. De entre todos los logros técnicos y científicos, los que verdaderamente generaron nuevos tipos arquitectónicos o, al menos, modificaron en gran medida los existentes fueron los conseguidos en el campo de la construcción y la estructura.

Los nuevos centros de producción necesitaban de espacios cada vez más diáfanos, que los sistemas tradicionales de madera y mampostería no eran capaces de solucionar. El desarrollo de la red de transportes igualmente necesitaba de nuevos puentes, más resistentes, de mayor luz y duraderos para un cada vez más intenso tráfico de mercancías. El hierro fundido se mostró como una solución muy eficaz para la construcción de puentes y fábricas y su uso se extendió también a otro tipo de edificios civiles, como iglesias y bibliotecas, y se utilizó como sistema "a prueba de fuego" sustituyendo paulatinamente las estructuras de entramados de madera y muros de fábrica.

Los incendios se habían convertido en algo trágicamente habitual en una industria incipiente en la que las medidas de protección aún no se habian impuesto. La mayor parte de las construcciones, incluso las industriales, se levantaban con estructura de madera y muros perimetrales portantes de fábrica de ladrillo o mampostería. La fábrica más avanzada y elegante de su época no fue ajena a ese sistema constructivo y esa fue precisamente la causa de su colapso. En efecto, en 1783 el arquitecto Samuel Wyatt y los ingenieros (y sus socios financieros) Boulton y Watt construyeron a orillas del Támesis (Surrey) la factoría Albion Mill [1] una industria dedicada a la producción de harina que pretendía su elaboración en cantidades sin precedentes en la historia. En su interior se encontraba la tercera máquina de vapor construida por la compañía Birminghan que producía la fuerza motriz necesaria para la molienda del grano de maíz. Albion Mill se había levantado con el fin de mejorar y superar el rendimiento de los molinos de harina, pero también se había configurado como un lugar social donde la aristocracia de Londres se

[1] La fábrica Albion Mill desde el Támesis. Grabado de 1791. Fuente: The British Museum image service.

[2] Dibujo de la patente por William B. Wilkinson, de "Improvements in the Construction of Fireproff Dwellings, Warehouses and Buildings" 1984. Publicado en Building: 3000 year of Design, Engineering and Construction. Bill Addis, 2007.

[3] Vivienda Coignet, en St. Denis, Francia 72, Rue Charles-Michels, 1853. Arquitecto: Théodore Lachèz; Constructor: Françoise Coignet, de "L'Ingénieur", 1 de noviembre de 1855, lámina XXXIII. Publicado en Concrete. The visión of a New Architecture. Peter Collins. 2004 
dejaba ver y donde las personalidades extranjeras eran invitadas a visitar las instalaciones, como hizo en 1786 Thomas Jefferson, futuro presidente de Estados Unidos. Había un consciente intento de generar un icono fabril dentro de la ciudad, algo en sí mismo verdaderamente novedoso. Ya no eran solamente los palacios o los edificios administrativos los que configuraban el entorno urbano, sino que se les añadía la fábrica como imagen de la más absoluta modernidad tecnológica. En 1791, la ciudad de Londres presenció horrorizada cómo un incendio devoraba lo que había sido su factoría estrella, y si bien hubo mucho rumores de un incendio provocado por el descontento de los molineros, según un informe de la época la catástrofe ocurrió al recalentarse unos cojinetes de la maquinaria de vapor, por un sobre esfuerzo para el que no estaba preparada.

Los incendios se convirtieron en una de las mayores preocupaciones de los propietarios y proyectistas y, si bien en un primer momento la madera se sustituyó por estructuras de fundición, hacia 1850 se había ido extendiendo la idea de que el hierro sin protección no era tan resistente al fuego como se pensaba. El departamento de bomberos de Londres se negaba a entrar en edificios incendiados con estructura de hierro por el peligro de hundimiento. En 1846 ya se había probado la eficacia de revestir con mampostería la estructura metálica a efectos de fuego, y se ensayaban diversos procedimientos con yesos y morteros de cemento para obtener idénticos resultados.

\section{El hormigón armado. Origen de las patentes: Wilkinson, Coignet y Monier}

La invención del hormigón armado se suele atribuir al constructor William Boutland Wilkinson (1819-1902), especialista en ornamentación y molduras de yeso y hormigón (al que llamaba "piedra artificial") quien, en un intento de dar respuesta al problema de los incendios, solicitó en 1854 la patente de un sistema que incluía armaduras de hierro para "la mejora de la construcción de viviendas, almacenes y otros edificios resistentes al fuego". Su técnica consistía en una serie de casetones de yeso que se comportaban como encofrados perdidos en los que se vertía hormigón sobre unas barras de hierro, generando, una vez fraguado, una losa nervada [2]. Wilkinson, en su intento de conseguir construcciones resistentes al fuego y económicas, construyó una verdadera losa nervada armada y supo reconocer de forma muy intuitiva las propiedades de resistencia a flexión del nuevo material. Fue el primero en disponer armaduras inferiores resistentes a flexotracción en los nervios de la losa, y realizó varios ensayos de deformación de sus estructuras, algo inusual en la época. Utilizó su modelo estructural en una vivienda en Newcastle en 1865, y constituyó una próspera empresa que mantuvo activa hasta principios del siglo XX pero nunca llegó a formalizar un sistema integral de construcción en hormigón armado.

[3]

[2]

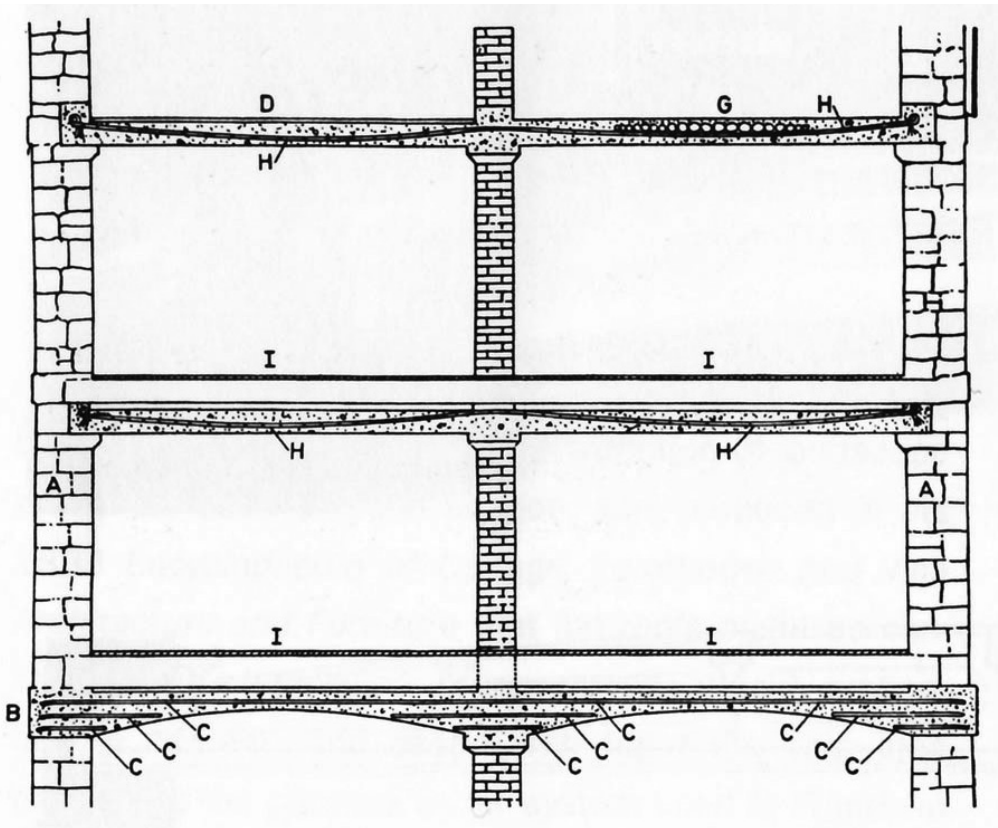

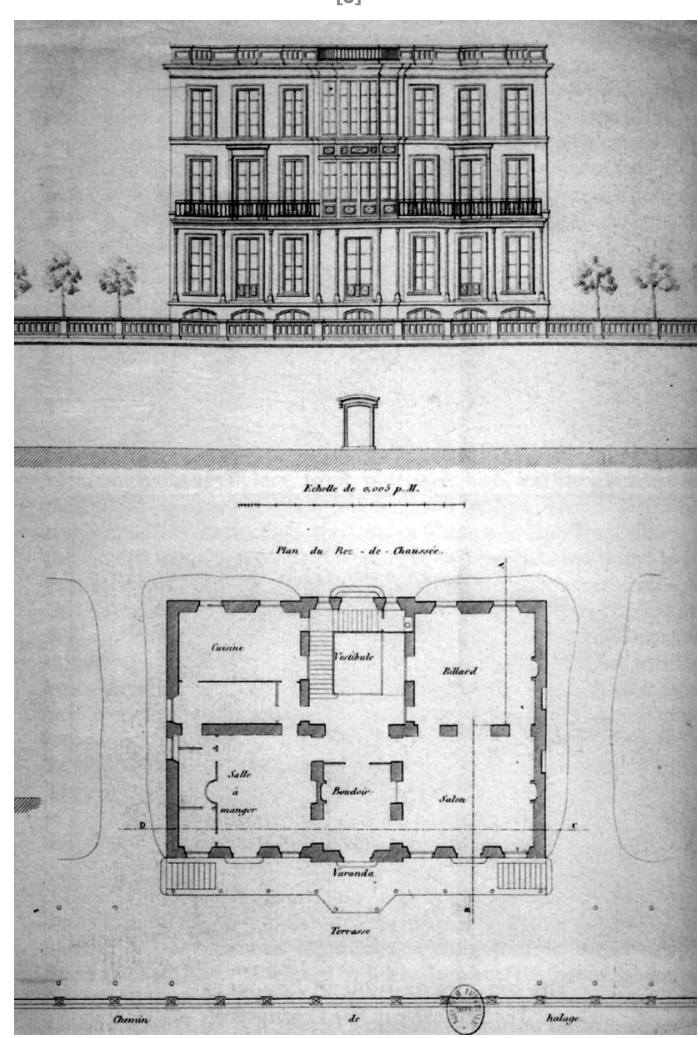


Unos años antes, en 1852, el industrial francés François Coignet (1814-1888) aplicó vigas de hierro en doble "T" en la construcción de la cubierta de su casa, en la fábrica Saint Denis, como refuerzo a la losa de hormigón de $30 \mathrm{~cm}$ de espesor que había diseñado. Si bien no podía considerarse hormigón armado, sí mostraba con total claridad hacia dónde se dirigían los esfuerzos de constructores, industriales y técnicos en esos años. Coignet se dio cuenta rápidamente del potencial económico que había en la utilización de estos sistemas de hierro y hormigón y en 1853 construyó una casa utilizando su invención [3]. La vivienda fue inspeccionada en 1855 por un comité de catorce arquitectos dirigidos por Henri Labrouste. $\mathrm{Su}$ dictamen no fue muy favorable exponiendo serias dudas sobre su seguridad estructural. ${ }^{1}$ Expuso su trabajo en la exposición de París de 1855 y al año siguiente patentó su técnica de hormigón armado. En 1861 comenzó a publicar sus trabajos. En 1874 los presentó en Estados Unidos bajo el título de Beton-Coignet. Description of the Material and its Uses in France and America, editado por John C. Goodridge jr, que más tarde sería su socio y presidente de la compañía New York Stone Contracting Co, depositaria y explotadora de las patentes de Coignet. La empresa construyó algunos de los edificios más notables de Nueva York, como el claristorio de la Catedral de San Patricio, el Museo Metropolitano de Arte y el Museo Americano de Historia Natural.

En 1877 Thaddeus Hyatt, industrial e ingeniero neoyorquino, desconociendo los trabajos de Wilkinson, publicó un libro de circulación privada donde se desarrollaba por primera vez un pensamiento científico y sistemático relativo a la naturaleza del nuevo material. ${ }^{2}$ Sus estructuras traslucian una notable comprensión del funcionamiento del hormigón armado. Dispuso barras de acero en la zona de tracción anclándolas adecuadamente en la zona de compresión, entendió la necesidad de disponer barras verticales en la zona de los apoyos y descubrió la esencia del trabajo conjunto del acero y el hormigón: ambos materiales poseen casi el mismo coeficiente de dilatación térmica.

Joseph Monier (1823-1906), un jardinero francés nacido en Saint-Quentin-de-Poterie, patentó en 1867 un "sistema de cajas-barreños móviles, en hierro y cemento, aplicables a la horticultura".3 Su "invento" consistía en la combinación de mallas de hierro y hormigón para la construcción de macetas, depósitos, estanques y otros productos de jardinería [4]. Había comenzado a experimentar con macetas de cemento y malla de alambre en 1849 y como muchos de sus contemporáneos, también de modo intuitivo, se dio cuenta del alcance de sus resultados. Así, después de su primera patente, siguió trabajando en nuevas aplicaciones y en 1868 patentó un sistema de fabricación de tubos y tanques; en 1869, paneles prefabricados para fachadas; en 1873, puentes para carros y puentes peatonales; ${ }^{4}$ en 1878, vigas; y el 15 de abril de 1886 un "sistema de construcción de casas fijas o portátiles, higiénicas y económicas de hormigón y hierro".5

Ese mismo año proyectó y levantó una vivienda experimental en el patio de su empresa, en la calle Pompe (París). Era un sistema muy ingenioso que consistía en construir un armazón metálico con la forma de la vivienda y luego, una vez encofrado, verter el hormigón. En realidad este procedimiento no suponía nada nuevo en sentido estricto: Henri Labrouste había construido las bóvedas de la Bibliothèque Sainte-Geneviève a base de cables entrelazados con yeso; sin embargo, lo novedoso estaba en la capacidad que tenía la propuesta de hormigón y alambre para aguantar cargas y presiones y no solamente el peso propio. El sistema fue la base de las estructuras laminares y permitía el uso del hormigón con una plástica que los sistemas lineales eran incapaces de conseguir. Sin embargo, Monier no era un gran empresario y no consiguió retener su invento y llevarlo más allá de los depósitos o elementos de jardinería. Malvendió su patente al alemán Conrad Freytag en 1884 (quien se la cedió a G.A. Wayss para su explotación en el norte de Alemania) y perdió la exclusiva de la explotación de su patente en Rusia, que por seis años le había ofrecido el Zar Alejandro II en 1880. En 1892 obtuvo una patente norteamericana para su invención, en un intento de hacerse con una parte del enorme mercado que para el nuevo material había en Estados Unidos. Pero no obtuvo resultados comerciales de forma directa y su sistema solo se estableció en Norteamérica de la mano de Wayss a través de las concesiones a E. Lee Heidenreich. En 1900 Heidenreich publicó el opúsculo Monier Constructions donde explicaba las ventajas del sistema derivado de las investigaciones alemanas y con el que intentó abarcar parte del mercado americano que casi había copado Ransome.

Monier desarrolló sus trabajos exclusivamente de forma empírica, lo que restaba eficacia a las armaduras que no siempre eran coherentes con los esfuerzos que debían soportar. Intentó aprovechar comercialmente sus invenciones fundando empresas y registrando sus patentes en otros países. En España introdujo una primera patente en 1884 y una mejora sobre la misma dos años después, con una descripción tan amplia que le permitía la construcción de prácticamente cualquier cosa en hormigón armado. El ingeniero militar Francesc Maciá i Llussà (1859-1933)
1 La vivienda está situada en el número 72 de la calle Charles-Michels, en St. Denis, París. Fue declarada Monumento Nacional en 1998 y aún se mantiene en pie.

2 El libro se titulaba: Account of Some Experiments with Portland-cement-concrete Combined with Iron: As a Building Material, with Reference to Economy of Metal in Construction, and for Security Against Fire in the Making of Roofs, Floors, and Walking Surfaces, editado en Londres en 1877 por Chiswick Press.

${ }^{3}$ Nombre y descripción de la patente $n^{\circ}$ 77.165 registrada por Monier el 16 de julio de 1867, doce años después de la presentada por Lambot. Es considerada la segunda patente registrada relacionada con el hormigón armado.

${ }^{4}$ En 1875 construyó la pasarela de Chazelet, considerada el primer puente de hormigón armado del mundo, con una luz de $16,5 \mathrm{~m}$ y un ancho de $4 \mathrm{~m}$.

${ }^{5}$ Nombre y descripción de la patente $n^{\circ}$ 175.513 de 15 de abril de 1886.

${ }^{6}$ Francesc Maciá, más conocido por su faceta politica como primer presidente de la Generalitat Catalana durante la II República, es uno de los pioneros en la introducción del hormigón armado en España. Maciá adquirió el privilegio exclusivo para España y sus colonias. El depósito aún permanece en servicio, tiene $1.000 \mathrm{~m}^{3}$ de capacidad y una planta circular de 25,30 m de diámetro. Sorprende el pequeño espesor de sus paredes de $6 \mathrm{~cm}$. Su construcción responde al sistema caracteristico de Monier de paredes reforzadas con malla de alambre.

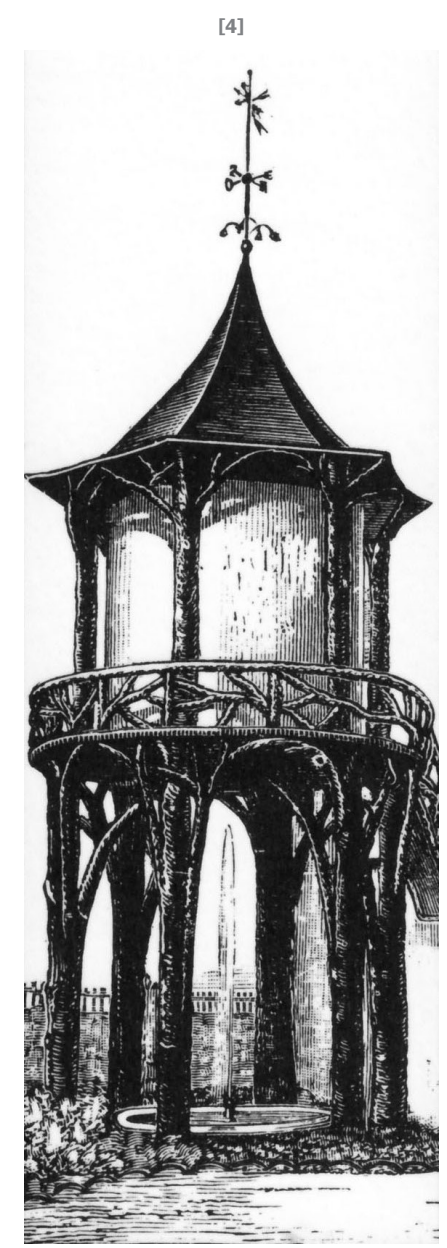




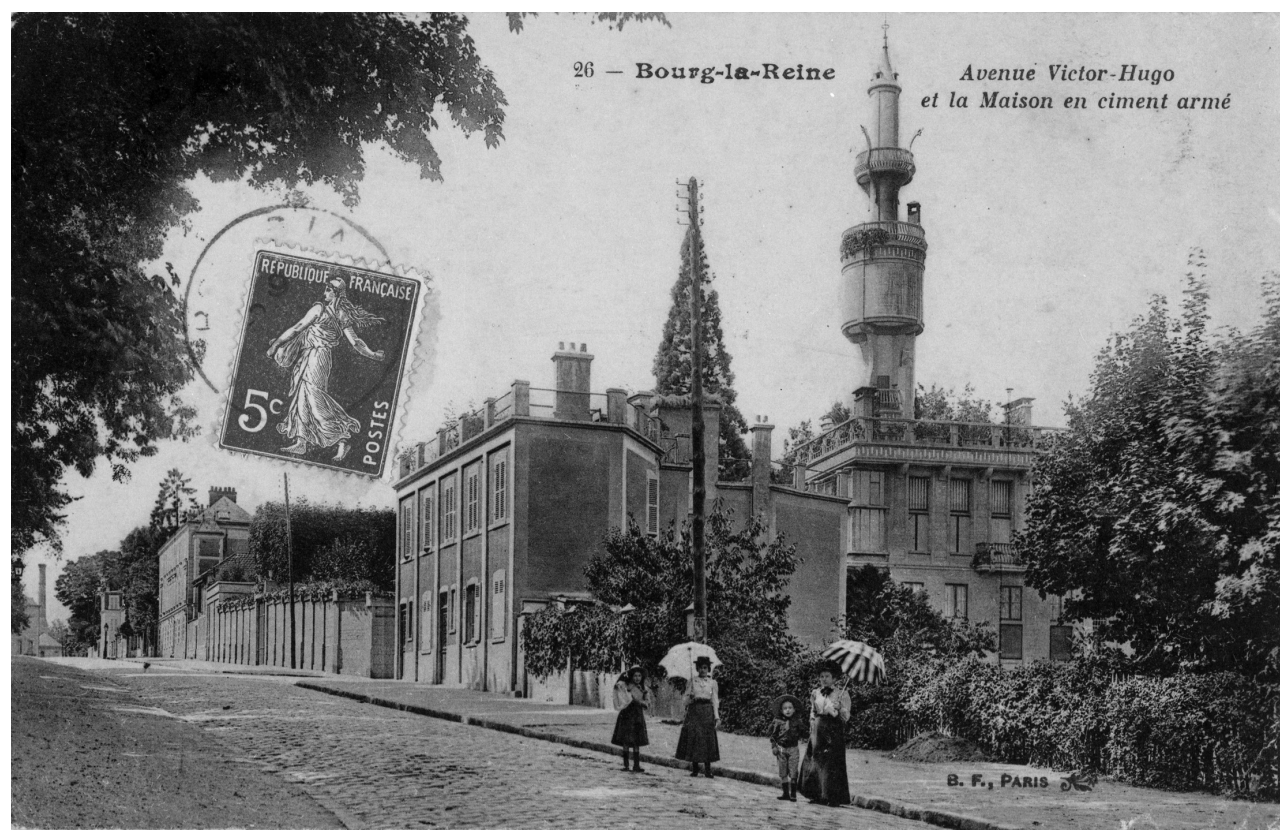

[7]

con la arquitectura del Movimiento Moderno: cubierta plana ajardinada, grandes ventanales, fachada no resistente y planta libre [7]. La expresión del hormigón como material nuevo aún no era algo en lo que pensaran los proyectistas del siglo XIX, al contrario, lo consideraban un material suficientemente plástico como para imitar diversos acabados, ellos "se dieron cuenta que era más económico producir piedras artificiales vertiendo hormigón que extrayendo piedra natural". ${ }^{8}$ Por eso, hasta la segunda década del siglo XX, la mayor parte de las fachadas de los edificios de hormigón armado buscaron imitar la construcción en piedra ahorrando, de esa forma, mano de obra. Tan solo las estructuras interiores de los edificios fabriles quedaban desnudas puesto que no se veían desde el exterior. Hennebique, sin embargo, intentó evidenciar el esqueleto estructural en algunas fachadas de fábricas, como en las hilanderías de Tourcoing de 1895 y Fives de 1896 [8] o la lavandería Duméril de 1902 [9], donde la estructura exterior aparece escasamente "adornada" con molduras o impostas. Más que la búsqueda de un lenguaje propio, era la necesidad de mostrar las virtudes de su invento y la capacidad de hacer transparentes las fachadas para convertirlas en fuente de iluminación natural. Estas decisiones en principio más comerciales que arquitectónicas- empezaron a marcar una tendencia en lo que sería el tipo de fábrica hasta las primeras décadas del siglo XX: un contenedor de pisos, en torno a siete, de planta longitudinal, grandes ventanas y estructura porticada, que adoptó el nombre de fábrica "monolítica" en referencia a los nudos rígidos. ${ }^{9}$

En Estados Unidos fueron Ernest L. Ransome, y posteriormente Albert Kahn, quienes desarrollaron este tipo edificatorio llevándolo a unas dimensiones desconocidas en Europa.
[7] Vivienda Hennebique en Bourg-la-Reine. Fuente: CNAM/SIAF/Cité de l'architecture et du patrimoine/archives d'architecture du XXe siècle. Tarjeta Postal, colección G. Delhumeau. Dossier : 076 Ifa 7777

[8] Hilandería de algodón Barrois Frères, quartier de Fives, Lille (Nord). Vista exterior. Fotografía anónima. Fuente: NAM/SIAF/ Cité de l'architecture et du patrimoine/Archives d'architecture du XXe siècle. Dossier : 076 Ifa 113/27 (doc. 3-A-040).

[9] Lavanderia industrial Duméril, Jaéglé et Compagnie, Vieux-Thann (Haut-Rhin), vista de la fachada principal. Fotografia anónima. Fuente: CNAM/SIAF/Cité de l'architecture et du patrimoine/Archives d'architecture du XXe siècle. Dossier : 076 lfa 25/9 (doc. 3-A-635).

[10] Fábrica Pacific Coast Borax Co. construida por E.L. Ransome. Arriba: primera fase de 1897. Abajo: segunda fase de 1903. En seis años la construcción masiva dio lugar a edificaciones permeables a la luz y ventilación llevando a fachada el esqueleto estructural. Fuente: Ransome Unit Construction. Ransome Engeenering Company. Nueva York. 1912. Fondo documental del autor.

[11] Patente $n^{\circ} 611.907$ de Hennebique en Estados Unidos: "Construcción de vigas, viguetas y similares" 1898. United States Patent and Trademark Office.
[8]

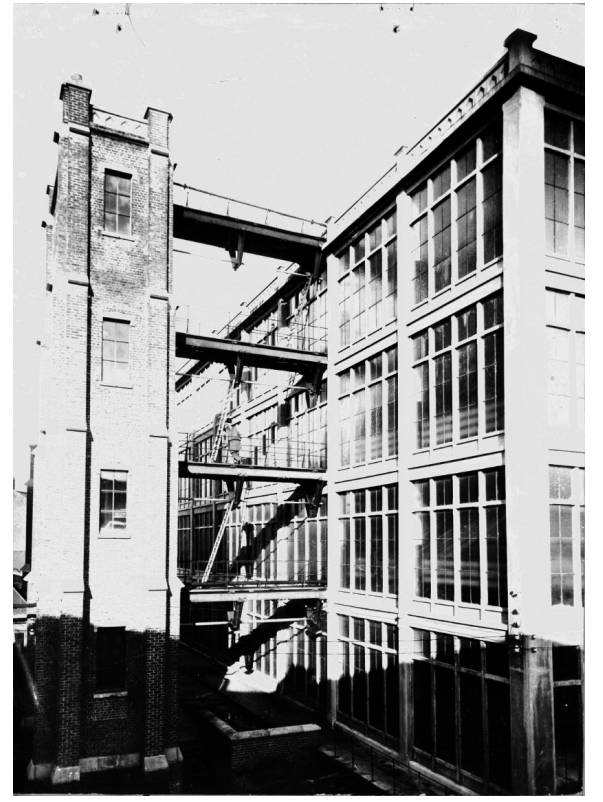

[9]

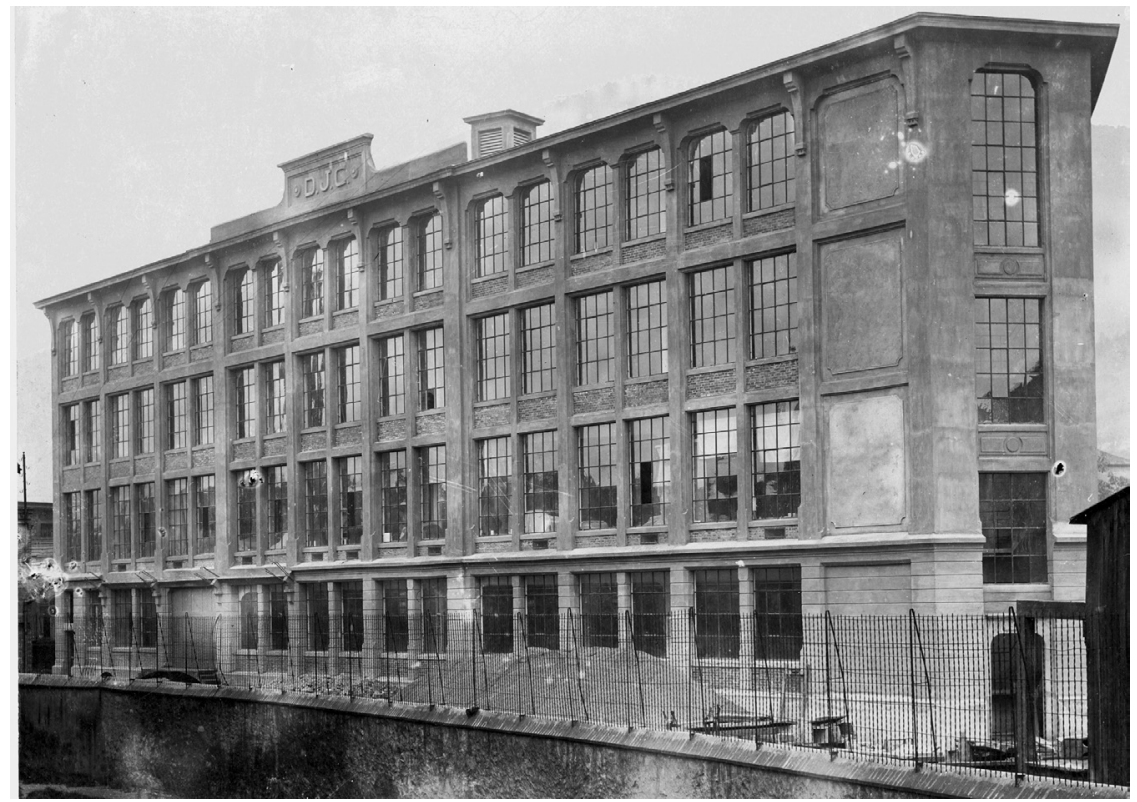



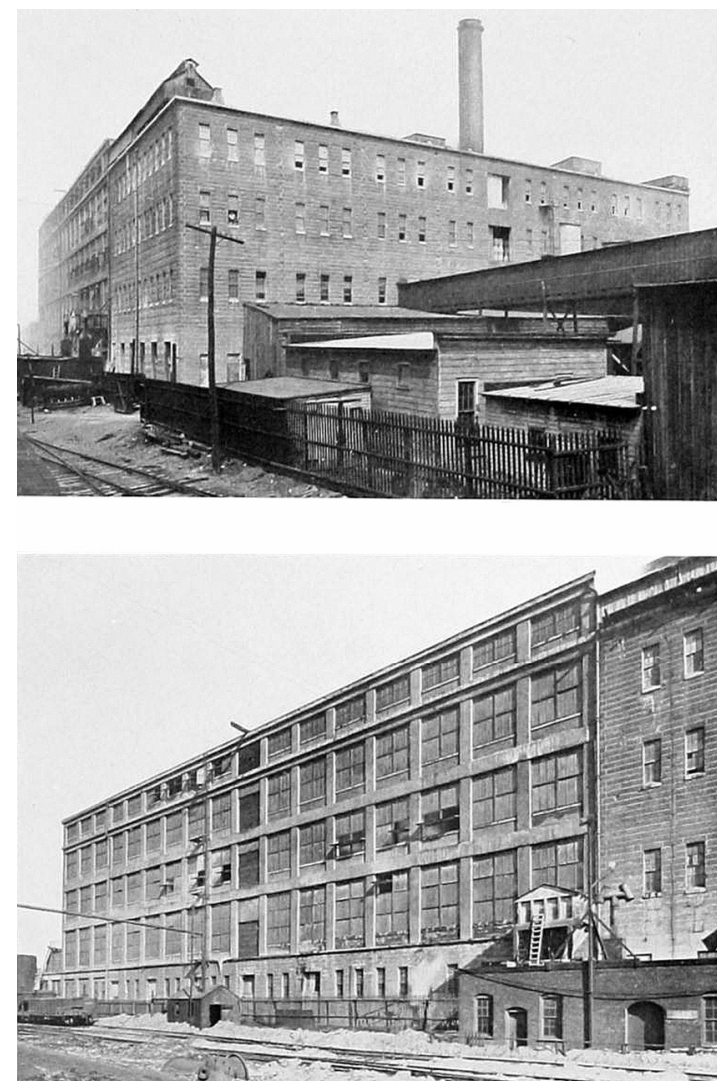

[10]

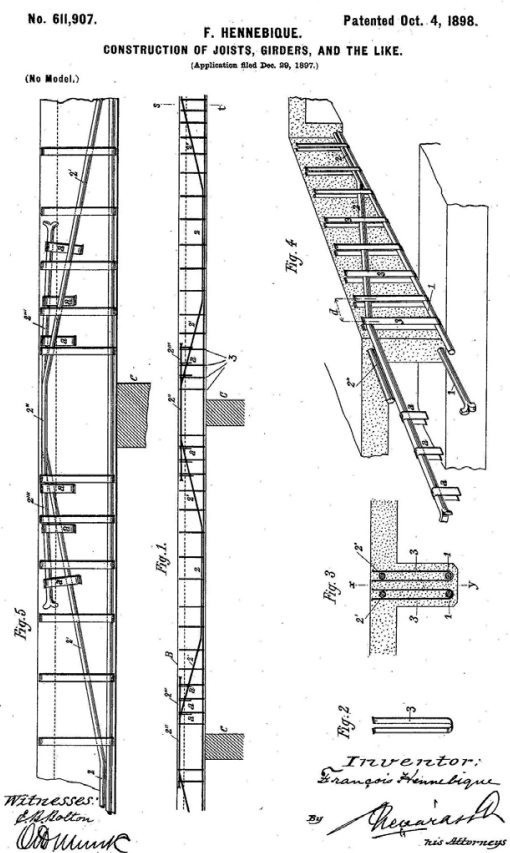

[11]
${ }^{8}$ BILLINGTON, David P. La torre y el puente: el nuevo arte de la ingeniería estructural, Cinter Divulgación Técnica, 2013, p. 164.

${ }^{9}$ Este tipo edificatorio duró hasta la taylorización de los sistemas de producción, la implantación de los trabajos en serie y las cadenas de montaje, que demandaban un tipo de edificio lineal y en una sola planta.

${ }^{10}$ En 1902, un edificio que habia construido cinco años antes para la Pacific Coast Borax Bayonne en Nueva Jersey, una empresa dedicada al refinado de colemanita, sufrió un espectacular incendio que atrajo la atención de toda la nación. El fuego fue tan intenso que el acero de las maquinas se derritió y el hierro de las instalaciones se fundió, pero la fábrica apenas sufrió daños porque estaba hecha de "hormigón armado incombustible". Fue una enorme publicidad para el nuevo material, para las compañías que lo producían y el triunfo y la justificación de la vida profesional de Ransome.
Ransome, originario de Inglaterra, construyó en 1886 dos pequeños puentes en Golden Gate Park, San Francisco, considerados los primeros puentes de hormigón armado en Norteamérica. Su trayectoria profesional le convirtió en el constructor de fábricas con estructuras de hormigón más reconocido en Estados Unidos durante los primeros años del siglo XX, aplicando sistemáticamente sus innumerables patentes. Los primeros edificios que proyectó eran de aspecto masivo y muy ligado a las primeras fábricas tradicionales. Paulatinamente comprendió las ventajas del esqueleto rígido de hormigón armado y fue liberando las fachadas de su carga muraria para convertirlas, al igual que Hennebique, en un entramado de vigas y soportes que flanqueaban grandes superficies acristaladas [10]. Costruyó también el Ingalls Building, el primer rascacielos de hormigón armado con acero trenzado, de 16 plantas y losas que actuaban como diafragmas frente al empuje del viento, constituyendo una estructura absolutamente monolítica. Ransome consiguió convencer de manera contundente de las ventajas ${ }^{10}$ de la aplicación del nuevo material en la construcción de edificios industriales y abrió el camino para que su discípulo más brillante, Albert Kahn, convirtiese la construcción de fábricas en un paradigma del Movimiento Moderno.

Hennebique comprendió, dado el éxito de la empresa y su rápido crecimiento, que era necesario delegar y creó la figura del Agente General, un empresario local con poder de decisión en cuestiones técnicas y libertad para contratar y dirigir sus propias obras. Esto, que fue clave para el sostenimiento de la multinacional del hormigón, fue también causa de cierto descontrol en las obras lejanas que terminaron por provocar accidentes mortales. En 1902 llegó a tener 290 concesionarios y 43 oficinas en Europa, 12 en Estados Unidos [11] y 10 por África y Asia. Durante los primeros años del siglo XX tuvo el monopolio de la construcción de obras en hormigón en Inglaterra. En España fue el ingeniero José Eugenio Ribera, mentor de Eduardo Torroja, el concesionario de Hennebique, desde 1897 hasta 1901, año en que fundó su propia empresa.

Las empresas concesionarias y la propia casa matriz tenían dos formas de trabajar: podían realizar sus propios proyectos, actuando como diseñadores o promotores, como en el edificio de calle Danton 1, en París, la sede social de la empresa y un intento de convencer al mundo de que con hormigón era posible construir también edificios de viviendas; o podían trabajar como meros contratistas, a las ordenes de otras empresas, ingenieros o arquitectos. Fue esta segunda opción la que demostró la flexibilidad del sistema dando respuesta a casi cualquier necesidad edificatoria

Una de las preocupaciones de Hennebique fue la ideación y desarrollo del voladizo que representaba tanto la resistencia como el monolitismo del hormigón armado y la garantía de 
su capacidad estructural. Un edificio especialmente singular con un voladizo de 4,25 metros fue la fábrica de piensos Weaver \& Company (1897-1898), en el muelle norte Swensea en Inglaterra [12]. Constituyó un hito en la construcción al ser el primer edificio de hormigón armado en Inglaterra y el primero, además, en utilizar el hormigón visto como elemento definidor de la fachada. La desnudez estructural, y la capacidad de adaptabilidad del sistema Hennebique, quedó manifiesta en edificios como los Almacenes y edificios de servicios marítimos de Bruselas (1904-1906) que preludiaban las fábricas con patios interiores; la Fábrica de zapatos de Boston de 1911, con un innegable parecido al edificio de Ford Motor Company Plant, Highland Park de Albert Kahn (1909-1910), o la fábrica Lingotto-Fiat, de Giacomo Mattè-Trucco.

El sistema se adaptó bien a los movimientos y "estilos" arquitectónicos. Al contrario de otras patentes con gran impronta formal, las estructuras de Hennebique podian pasar desapercibidas, estaban al servicio de los diseñadores y ese precisamente fue uno de los pilares de su éxito. Sus estructuras tanto valían para levantar un edificio neoclásico o una construcción Moderna. La estructura monolítica porticada permitió la existencia de la cubierta plana, la liberación del cerramiento ( $\mathrm{y}$, consecuentemente, la horizontalidad de las ventanas) y una organización de volúmenes y plantas libres.

Todos los productos de Hennebique se fundamentaban en su propia y exitosa experiencia en obra. No existía un cálculo teórico y profundo detrás de su sistema, algo que además despreciaba, su proceso creativo se basaba en las pruebas de carga [13] y los experimentos acumulativos: como las formas habian funcionado, en la siguiente generación de productos se iba más allá, haciendo estructuras más ligeras; esta manera de trabajar tenía un indudable valor comercial, pero suponía un total descontrol en la reducción de materiales. En realidad, en esos años, casi todo lo que se sabía del hormigón era empírico. Algunas de las estructuras así diseñadas colapsaron y el prestigio de la firma Hennebique empezó a decaer de tal manera que la empresa apenas sobrevivió a su fundador.

En 1901 se derrumbó un diseño de Hennebique en Basilea, con numerosas pérdidas de vidas y con repercusiones en toda Europa, lo que supuso el fin de la hegemonía de su compañía. En 1905 se produjo el hundimiento del Tercer Depósito del Canal de Isabel II en Madrid, obra de José Eugenio Ribera con el sistema Hennebique [14], causando 30 muertos; y aunque el informe redactado por el premio Nobel y perito ingeniero José Echegaray exculpase a los técnicos, produjo una gran desconfianza con los sistemas de hormigón retrasando su uso en España. Pero no solo el sistema Hennebique fallaba, el de Matrai en la pasarela de Suffren o el de Cottancin en los almacenes Pra en Santiago de Chile también colapsaron mortalmente.

No obstante, el trabajo de Hennebique, tanto en el hormigón armado como en el concepto empresarial, supuso el impulso definitivo para el uso del nuevo material, dándole mucha importancia a los medios promocionales. Fue el primero en utilizar masivamente la publicidad directa a través de una publicación propia que se editó ininterrumpidamente desde junio de 1898 hasta agosto de 1939: Le Béton Arme [15]. Con su ingente trabajo consiguió demostrar que el hormigón armado era un material apto para todo tipo de edificaciones civiles, obras públicas e incluso barcos y pantalanes. Hennebique murió en París, el 7 de marzo de 1921. A partir de su muerte apenas existen referencias técnicas que mencionen su trabajo, excepto breves notas históricas. Su empresa cerró en 1967.

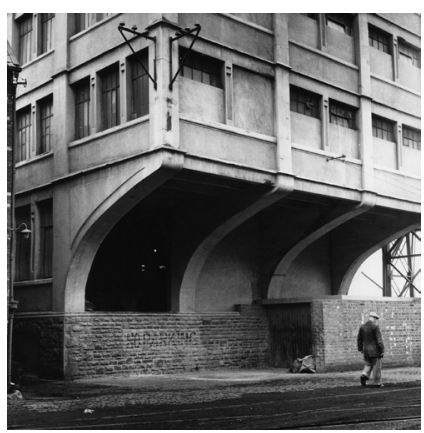

[12]
[13]

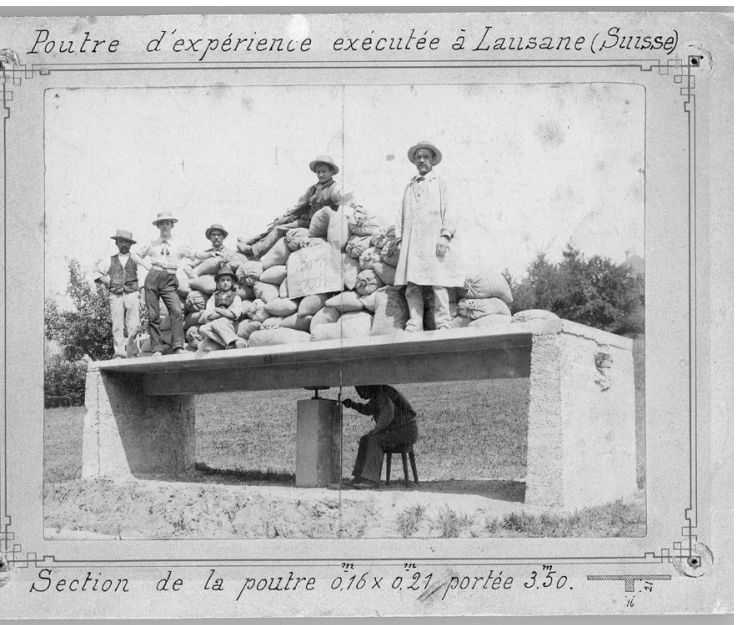

[14]

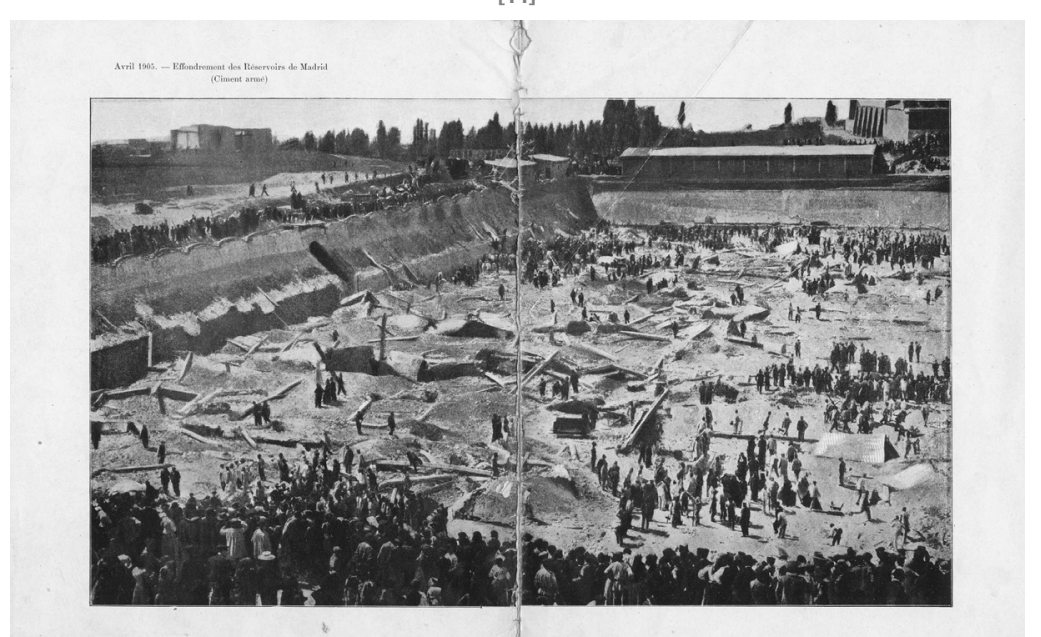


[12] Fábrica de Piensos Weaver \& Company Muelle Norte, Swansea, West Glamorgan. Vis ta del Voladizo. Fotógrafo: Galwey, Reginald Hugo de Burgh 1959. Fuente: Architectural Press Archive / RIBA Library Photographs Collection. RIBA50016.

[13] Prueba de carga sobre viga. Lausanne: vista de la viga experimental (sección de 0,16 $\mathrm{m} \times 0,21 \mathrm{~m}$; luz de $3,50 \mathrm{~m}$ ). Fotógrafo desconocido. Fuente: NAM/SIAF/ Cité de l'architecture et du patrimoine/Archives d'architecture du XXe siècle. Dossier: 076 lfa 60/10 (doc. 6-J-078).

[14] Hundimiento del tercer depósito del Canal de Isabel II, Madrid. Imagen de la revista Béton Armé de abril de 1905. Fuente: NAM/ SIAF/ Cité de l'architecture et du patrimoine/ Archives d'architecture du XXe siècle. Dossier: 076 Ifa 138/21 (doc. 6-J-001).

[15] Portada de la Revista Béton Armé $\mathrm{n}^{\circ} 177$ febrero de 1913. Fondo documental del autor.

[16] Silo de grano (cereales). Ludwigshafen. Rhein. 1914. Ing. Wayss und Freytag. De LANGEWIESCHE, Karl Robert. Bauten der Arbeit und des Verkehrs aus Deutscher Gegenwart,1929, Leipzig. Fondo documental del autor.

[17] Losa plana sobre soportes fungiformes. Arriba, esquema de C.A.P. Turner. Centro 224 y 225 capitel fungiforme de C.A.P. Turner con el ábaco característico. Abajo, esquema de Robert Maillart. Centro 226 capitel fungiforme de Robert Maillart. Publicado en la Schweizerische Bauzeitung el 22 de mayo de 1926.

\section{El cientificismo alemán. Las primeras teorías de cálculo. Wayss und Freytag}

En 1885, el joven ingeniero berlinés A.G. Wayss (1851-1917) conoció el sistema Monier durante su presentación en la Exposición Industrial de Amberes; poco después adquirió los privilegios de explotación de la patente. A partir de ese momento, Wayss inició una expansión internacional y consiguió hacerse con el mercado del hormigón en Centroeuropa. En 1893 se asocia con C. Freytag para formar la compañía Wayss und Freytag convirtiéndose en la empresa de hormigón armado más importante en Alemania hasta la Primera Guerra Mundial. Su contribución más notable fue entender el hormigón armado como un material que se podía someter a procesos de conocimiento científico, dándole la máxima importancia a la investigación, comportamiento estructural y métodos de cálculo.

Trabajaron con el ingeniero civil Mathias Koenen, que en ese tiempo intentaba conjeturar el momento flector de una losa con varillas de hierro en su plano inferior, y el coeficiente de dilatación de los materiales que la componían (hormigón y hierro). Había sido designado como jefe de obra para la construcción del Reichtag, obra del arquitecto Paul Wallot (1882) y pretendía aplicar los principios de Monier para los forjados ignífugos. Wayss und Freytag también colaboró con Johann Bauschinger (matemático e Ingeniero Civil), director del Politécnico de Múnich y con Emil Mörsch autor de varias teorías sobre el hormigón armado, siendo las más importantes aquellas sobre el lugar geométrico de las fibras deformadas de una viga, y las teorías sobre cortantes y la torsión. Sus investigaciones le hicieron formar parte de la comisión que redactó en 1904 las primeras normas alemanas sobre hormigón armado.

El interés de los alemanes por el cálculo teórico frente al pragmatismo experimental de Hennbique dio lugar a dos líneas divergentes de pensamiento estructural, y es el inicio de las oficinas de cálculo y los proyectistas frente a las grandes empresas que vendían el sistema basado exclusivamente en la experiencia. Esta búsqueda de la razón numérica fue, a su vez, la mayor limitación de los alemanes debido a que solo proyectaban y construían aquello que podían justificar desde el cálculo, con lo que acortaban el abanico de soluciones estructurales. Por la misma razón desecharon los forjados planos sobre soportes fungiformes, a pesar de que empresas alemanas trabajaron con el ingeniero ruso Artur Ferdinandovitch Loleit, inventor de uno de aquellos sistemas. Sencillamente no encontraron una formulación matemática suficientemente fiable que les permitiese el desarrollo de ese tipo estructural. [16]. Wayss y Koenen rehicieron los diseños de Monier para encajarlos en sus ecuaciones de cálculo y obviaron todo lo que era intuitivo; en 1887 publicaron sus resultados en un texto considerado como la primera publicación técnica que describía con precisión el comportamiento mecánico del hormigón armado: Das System Monier, Eisengerippe mit Cementumhüllung "Monierbroschüre". El punto de
[15]

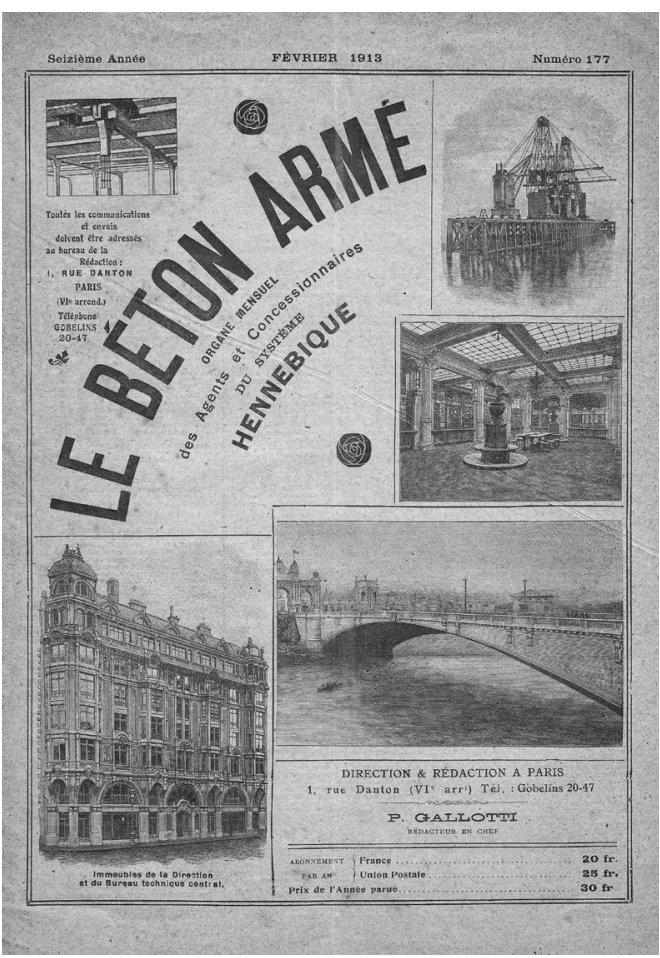

[16]

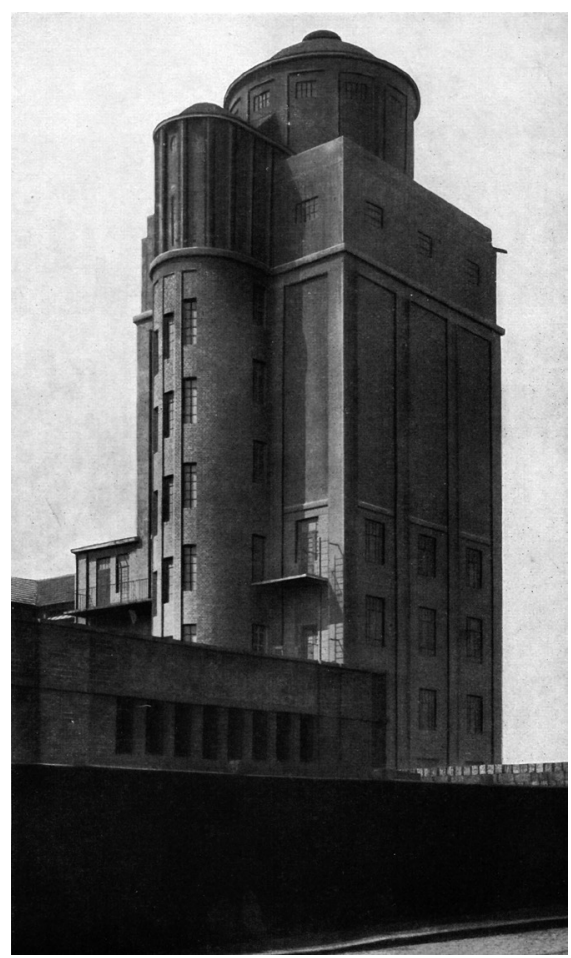

[17]

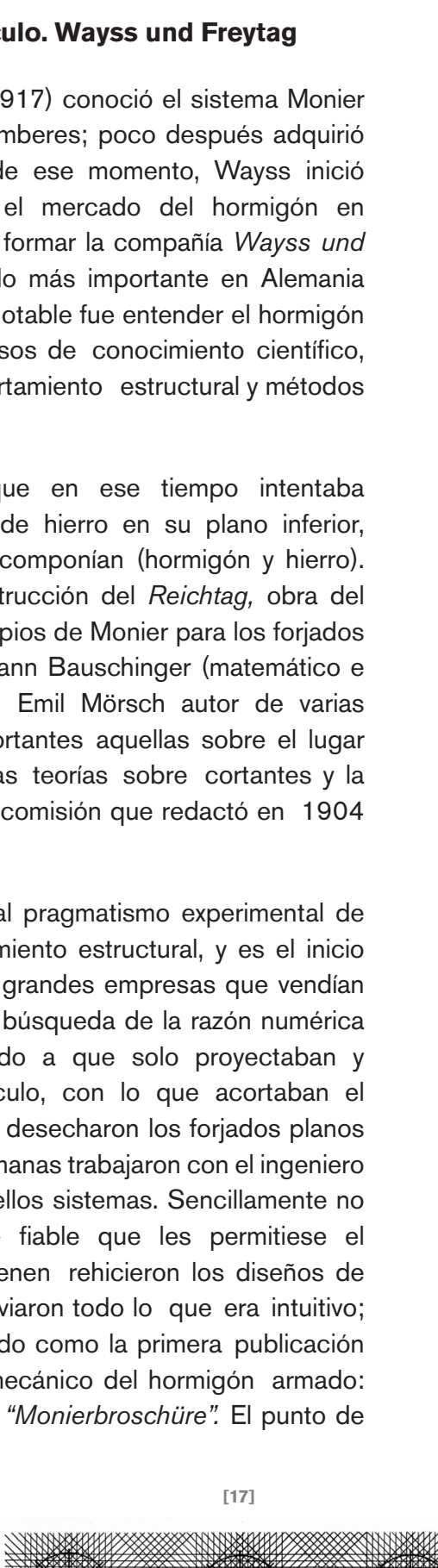

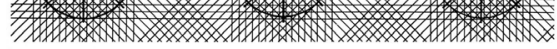
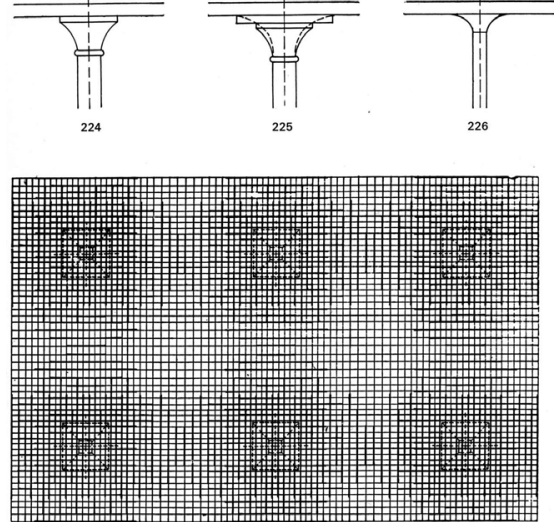

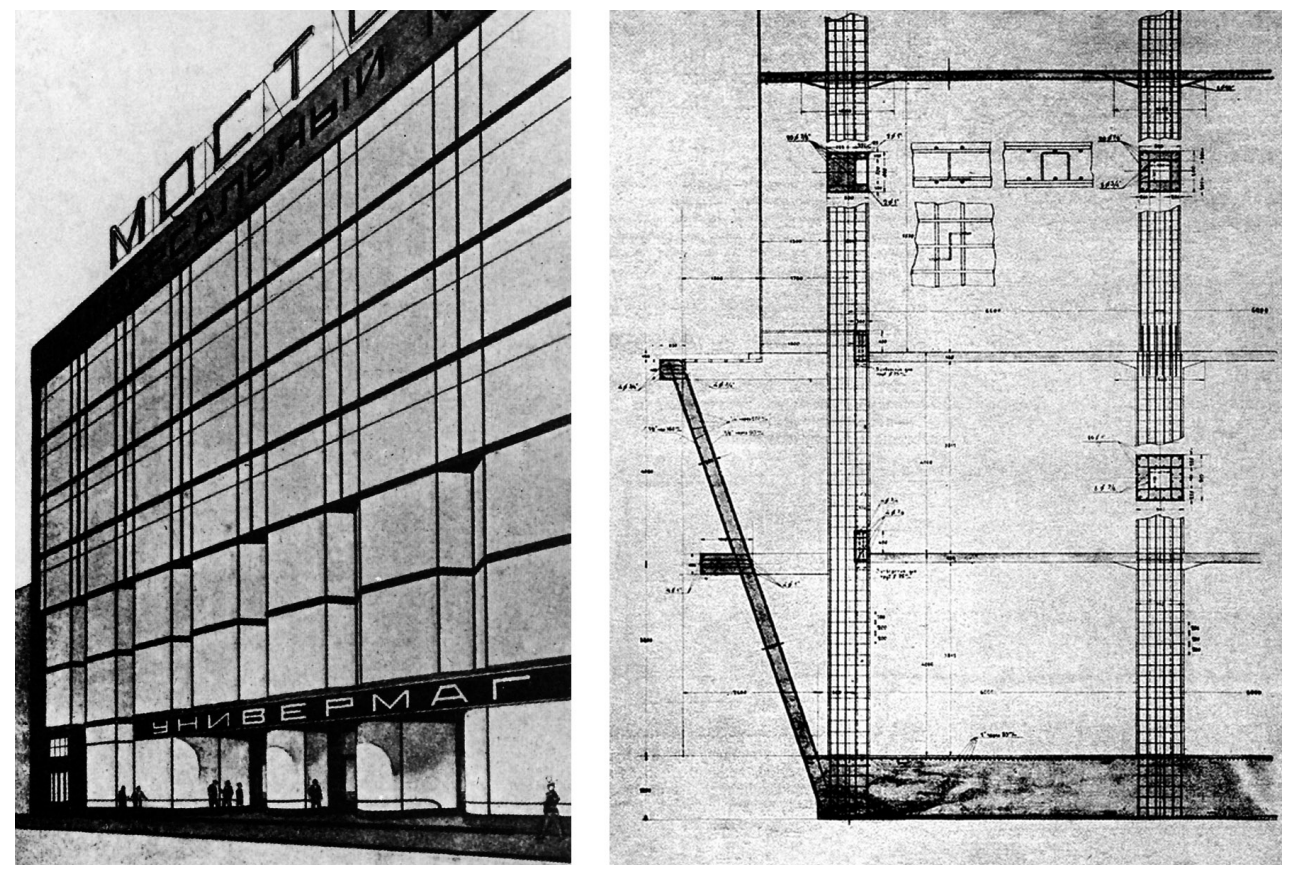

[19] inflexión en el desarrollo de las patentes se produce en 1892. En ese año presentan una licencia industrial en la cual describían el comportamiento del hormigón armado en cuanto a adherencia y transmisión continua de fuerzas entre el hierro y el hormigón. Ya en 1884 Ransome había solicitado una patente para barras cuadradas retorcidas en frío que mejoraba la unión entre los elementos. A partir de ahí se generó una segunda y apasionante carrera de patentes para diseñar las armaduras con mayor adherencia y conseguir mayor resistencia estructural.

Según Wayss, todo tenía que ser científicamente formulado. El tiempo le dio la razón; mientras la empresa de Hennebique languidecía hasta desaparecer en 1967, Wayss und Freytag entraba indemne en el siglo XXI posicionándose como una de las mayores ingenierías del mundo ${ }^{11}$. La empresa sigue en activo.

\section{La losa sobre soportes fungiformes}

Uno de los objetivos de los proyectistas de almacenes y fábricas de principios del siglo XX fue la obtención de la planta diáfana. Las grandes luces, que favorecían una planta vacía de estructura, tenían como consecuencia la existencia de estructuras con importantes cuelgues, generando espesores virtuales de forjado incompatibles con la optimización espacial y económica que requerían aquellos edificios. Tres ingenieros, de forma independiente, dieron con una solución: evitar dichos cuelgues haciendo que la losa de forjado fuese un elemento estructuralmente activo y no pasivo como hasta ese momento. En Estados Unidos, en 1906, Claude Allan Porter Turner construyó el primer edificio con ese sistema, que había estado estudiando desde 1905, el edificio Bovey, en Minneapolis. En 1907 Artur Ferdinandovitch Loleit lo utilizó en la fábrica textil Bogorodsk-Glukhovskoe, cerca de Moscú. En 1908 Rober Maillart, sin conocer el trabajo de C.A.P. Turner ni el de Loleit, dio con una solución aparentemente idéntica. En los tres casos el principio estructural era el mismo y consistía en que la losa de forjado fuese capaz de transmitir los esfuerzos a los soportes sin necesidad de vigas. Esto era posible mediante la colocación estratégica de armaduras en ambas caras del elemento, pero generaba un problema complejo: el punzonamiento. Para solucionar este esfuerzo la carga debía entregarse gradualmente al soporte siguiendo una trayectoria hiperbólica. Maillart comprendió que la trayectoria de las cargas debía quedar comprendida dentro de esta curva teórica y dispuso de una amplia selección de formas definidas por parámetros puramente de ejecución. Las armaduras de la losa las dispuso formando cuadrícula a $90^{\circ}$ y siguiendo la dirección de los ejes principales de la situación en planta de los soportes; de esta manera podía transmitir las cargas a los pilares desde cualquier dirección [17].

Los tres sistemas diferían fundamentalmente en la disposición de las armaduras. Maillart, de una forma muy racional, las disponía en cuadrícula ortogonal en la zona traccionada y reforzaba las zonas de punzonamiento con una parrilla de armaduras, también ortogonales y paralelas a la parrilla base, que se conectaban a $45^{\circ}$ con la armadura inferior resolviendo la transmisión del cortante. En función de las cargas, los capiteles de Maillart podían crecer junto con las armaduras de punzonamiento.
${ }^{11}$ Actualmente, solo el departamento de ingenieria, tiene un volumen de negocio de 300 millones de euros y 700 empleados. La firma es un conglomerado de múltiples empresas con una facturación de 7.000 millones de euros. Es un referente en el diseño, cálculo y construcción de túneles.

12 Loleit era ingeniero y matemático e intentó justificar sus experiencias con este tipo de estructuras mediante la aplicación del método de Grashof, pero no convenció a los alemanes a pesar de insistir en que también habia ideado un método de cálculo propio. 
Imagen obtenida de BILL, Max, Robert Maillart Brücken und Konstruktionen,1969.

[18] Patente $n^{\circ} 1003384$ de C.A.P. Turner en Estados Unidos: Steel Skeleton Concrete Construction, 1911. Fuente: United States Patent and Trademark Office.

[19] Almacenes Mostorg, de 1927. Perspectiva y sección estructural de proyecto. De KHAN-MAGOMEDOV, Selim O. Pioneers of Soviet Architecture: The Search for New Solutions in the 1920s and 1930s, 1987.
Turner, sin embargo, utilizaba una disposición radial de refuerzos y armaduras que "cosía" todos los apoyos de los soportes. En realidad funcionaba como una red de vigas planas embebidas en la losa. El sistema de Turner tenía problemas de punzonamiento para cargas fuertes por lo que incorporó un ábaco de transición entre la losa y el soporte. Cuando las sobrecargas podían deformar excesivamente la losa, Turner introducía una retícula de barras de acero ortogonal respecto de los lados de la losa como algo excepcional.

Tanto Maillart como Turner fueron muy fieles a sus respectivas invenciones. Introdujeron mejoras o las adaptaron a las condiciones de geometría y espacio de los proyectos que realizaron. Ambos protegieron sus trabajos mediante patentes, Maillart el 10 de enero de 1909, después de un año de pruebas con óptimos resultados, en Suiza y con el número 46928 bajo la denominación de Beamless Deck. Turner a su vez protegió su sistema mediante una patente presentada en Estados Unidos, el 11 de junio de 1907 y autorizada el 12 de septiembre de 1911 bajo el número US. Patent 1003384 y la denominación Steel Skeleton Concrete Construction.[18]

Loleit, sin embargo, no patentó ninguna de sus creaciones. En Rusia no tenía competencia y la empresa alemana para la que trabajaba no tenía interés en su sistema por carecer de un cálculo convincente ${ }^{12}$. Él, además, no utilizó indiscriminadamente su invento sino que lo fue variando según las necesidades. Para Loleit, el sistema, en vez de ser un conjunto de elementos definidos, era una idea que se adaptaba y construía según las necesidades de cada proyecto. Así, en el proyecto de la fábrica textil BogorodskGlukhovskoe, de 1907, la losa estaba armada con una retícula ortogonal base, en la dirección de los ejes de los soportes, y un refuerzo a punzonamiento en cuadrículas a $45^{\circ}$ respecto de los mismos. Sin embargo, unos años después, en el edificio para los Almacenes Mostorg, de 1927 [19], el diseño de la estructura se refinó y racionalizó; la armadura tenía una disposición muy similar a la usada actualmente. Incorporaba algo que hasta ese momento no se había visto: una capa de armadura superior para reparto de carga, una capa inferior de refuerzo a deformación de vano y otra capa para resistir el punzonamiento. En la medida en que Loleit fue acumulando experiencias con la práctica, sus diseños estructurales se hicieron más estrictos y elegantes.
[18]

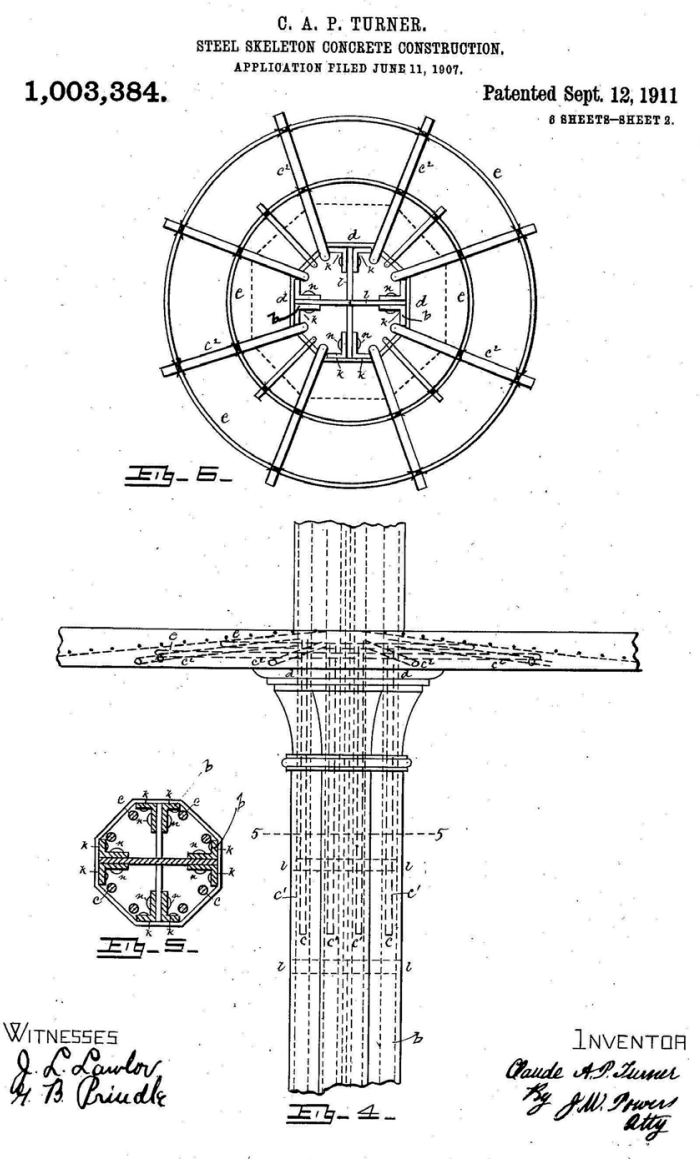

[20]
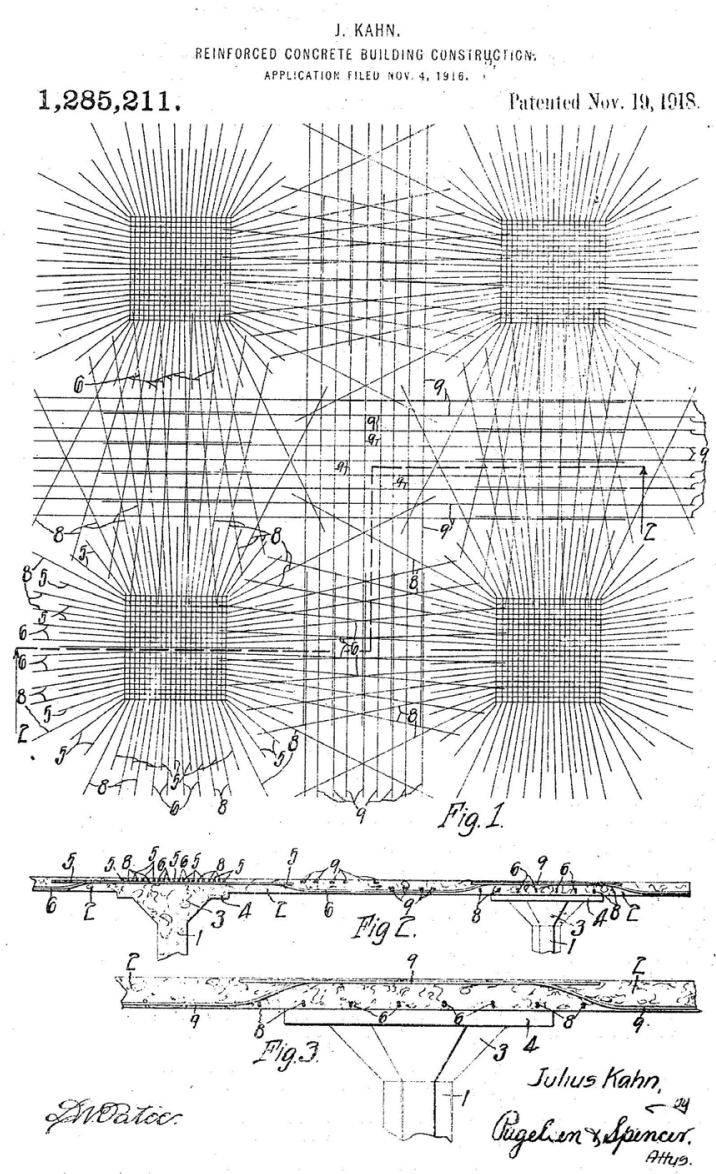
El negocio de las patentes generaba grandes beneficios y, si bien Maillart por sus circunstancias personales no pudo aprovecharse de ello, Turner sí lo hizo, llegando a construir en 1913 alrededor de mil forjados. Con este potencial económico, se inició otra guerra de patentes y cualquier variación, por nimia que fuese, daba lugar a una nueva solicitud de registro. Entre las más notables, por su trascendencia en Europa, está la de Julius Kahn, hermano de Albert y Moritz Kahn, presentada en 1916 y aprobada el 19 de noviembre de 1918 bajo el nombre de Reinforced concrete building construction, con el número US Patent 1285211 [20]; fue la que se implantó en Reino Unido de mano de la filial inglesa de la Trussed Concrete Steel Company, la ingeniería de los hermanos Kahn.

El sistema de losa fungiforme fue de gran importancia en el desarrollo de las posteriores fábricas europeas que aspiraban a tener plantas diáfanas ${ }^{13}$, y el modelo de referencia fue el de Turner, que era menos eficaz y elegante ${ }^{14}$ que los de Maillart o Loleit. Las razones de esto tenemos que buscarlas en la pujante industria norteamericana que empezaba a instalarse en Europa, sobre todo en Inglaterra, y que traía sus propias referencias, y en el impacto que causó la publicación en Inglaterra, en 1917, del libro The Design and Construction of Industrial Building de Moritz Kahn. ${ }^{15}[21]$

\section{El fin de las patentes: la reglamentación}

En 1906 se registraron solo en Francia 262 patentes relacionadas con el hormigón armado. La gran cantidad de licencias a nivel mundial y la ausencia de una reglamentación nacional producían verdaderos conflictos a la hora de controlar los costes, medidas de seguridad y normas de adjudicación en las obras públicas y edificios oficiales, principales clientes y destinatarios de las nuevas tecnologías. Pronto se vio la necesidad de establecer criterios objetivos de medida y control que permitiesen liberarse de las restricciones de una patente, y que garantizasen la seguridad de los edificios, las estructuras y las personas. La primera en redactarse fue la suiza Provisoriche Normen für Projektierung Ausführung und Kontrolle von Bauten armiertem Beton (EMPA) de 1903 y la siguiente fue la prusiana Bestiurmugen für die Ausführung von Konstructionen aus eisenbeton in Hochbau, de 1904. Sin embargo, la normativa que mayor influencia tuvo en Europa fue la francesa.

La administración francesa creó una comisión interministerial que estudió el problema. Dicha comisión estaba formada entre otros por Considère, ingeniero jefe de Puentes y Caminos, y Hennebique. Desde el primer momento hubo conflicto de intereses entre ellos y sobre qué esfuerzos estructurales debían considerarse en la reglamentación. Finalmente Considère impuso que se debía tener en cuenta, en el cálculo de las deformaciones, la resistencia del hormigón a tracción. En menos de veinte años, el hormigón armado, sujeto a patentes y ensayos y sin normativa alguna, se vió investido de un corpus reglamentario y del poder legal de las ordenanzas públicas. Fue la Circular Ministerial de 20 de octubre de 1906, y en ella se dividían por primera vez las funciones de constructores y proyectistas.

En 1904 la Asociación Alemana de Arquitectos e Ingenieros, junto con la Asociación Alemana de Hormigón, redactó una propuesta de normalización para las estructuras de hormigón armado. Sin embargo, no será hasta 1932 cuando se formule la primera norma DIN 1045 sobre diseño de estructuras de hormigón armado, bajo la dirección de Emil Mörsch. En 1915 con idéntica finalidad se redacta el Código de la Ciudad de Londres que es el origen de las actuales British Standard; desde 1907 Reino Unido había contado con una ordenanza no oficial que permitió cierta independencia de las normativas europeas. Se trataba del Report of the Joint Committee of Reinforced Concrete.

En Estados Unidos se desarrolló un programa de investigaciones formado por once universidades entre 1903 y 1910. Durante los siguientes cinco años se realizaron ensayos sobre edificaciones. Finalmente, en 1917, bajo el patrocinio de la American Society for Testing and Materials y representantes de los ingenieros civiles, ingenieros ferroviarios y fabricantes de cemento, se publicó una primera normativa: Standard Building Regulations for the use Reinforced Concrete. La consolidación del sistema de normas de hormigón ocurrió en 1947 con la edición del primer reglamento del American Concrete Institute, el ACl-318.

La circular francesa fue adoptada como normativa nacional por diversos países mientras redactaban sus propios reglamentos. Italia la usó hasta 1907, Rusia hasta 1915 y España hasta 1939, año en que se publicó una instrucción provisional, vigente hasta 1944. En esa fecha se aprobó definitivamente la primera Instrucción de Hormigón Armado Española, cuyo redactor fue casi exclusivamente Juan del Corro ${ }^{16}$ y que apenas supuso variación respecto de la ordenanza de 1939.
${ }^{13}$ El sistema de losas sobre soportes fungiformes alcanzó su máxima expresión en fábricas como la Boots Wets de Owen Williams (Nottingham, 1930), la Van Nelle de J. A. Brinkman y L.C. van der Vlugt con el ingeniero Jan Gerko Wiebenga (Rotterdam, 1930), o los Almacenes Schunck de Josephus Peutz (Heerlen, 1933).

14 En la actualidad la construcción en losa utiliza un entramado de armaduras similar al propuesto por Maillart estando en desuso el planteamiento de Turner.

15 Moritz Kahn había llegado a Londres en 1907 para fundar la filial inglesa de la Truscon y abarcar el negocio europeo y asiático. El libro, que publicó en 1917 con un marcado carácter publicitario, contenía un detallado estudio sobre el diseño y construcción de fábricas y una amplia documentación gráfica sobre el sistema de losa sobre soportes fungiformes desarrollado según la patente de Julius Kahn (su hermano) a partir de las experiencias de C.A.P. Turner.

16 Juan del Corro fue director de la Escuela Técnica Superior de Arquitectura de Madrid entre 1972 y 1980.

[20] Patente $n^{\circ} 1.285 .211$ de Julius Kahn en Estados Unidos: "Construcción de edificios de hormigón armado" 1918. Fuente: United States Patent and Trademark Office.

[21] Vista interior de uno de los edificios de la Ford Motor Co, Detroit Michigan publicada en el libro KAHN, Moritz. The Design and Construction of Industrial Building, 1917. Fondo documental del autor. 
El hormigón había dejado de ser un material secundario, de jardinería y de protección frente al fuego y había ganado la partida frente a otros materiales estructurales, fundamentalmente por su fácil producción y la necesidad de una mano de obra no muy especializada. A este surgimiento había contribuido una fuerte campaña publicitaria y sus enormes prestaciones comparadas con su bajo coste de fabricación. En Europa y Norteamérica la revolución industrial había dado paso al desarrollo económico. Se necesitaban puentes y carreteras que facilitasen el transporte, se incrementaron los puertos, los edificios de abastecimiento y los depósitos. Las distintas administraciones se dieron cuenta de que no podían dejar en manos privadas la potestad del desarrollo de sus países y decidieron, en las dos primeras décadas del siglo XX, liberalizar las patentes de hormigón armado para que la enorme cantidad de obras públicas fuesen controladas exclusivamente por la administración.

Con el advenimiento de las reglamentaciones nacionales comenzó el declive de los sistemas patentados; se pusieron al alcance de los proyectistas los métodos de cálculo y comprobación normalizados para el diseño libre de estructuras de hormigón. Fue el momento en que los ingenieros estructurales se convirtieron en los proyectistas y directores de sus obras. Fue el momento en que algunos arquitectos visionarios se dieron cuenta de las posibilidades que ofrecía el hormigón armado para pensar en una nueva arquitectura.

[21]

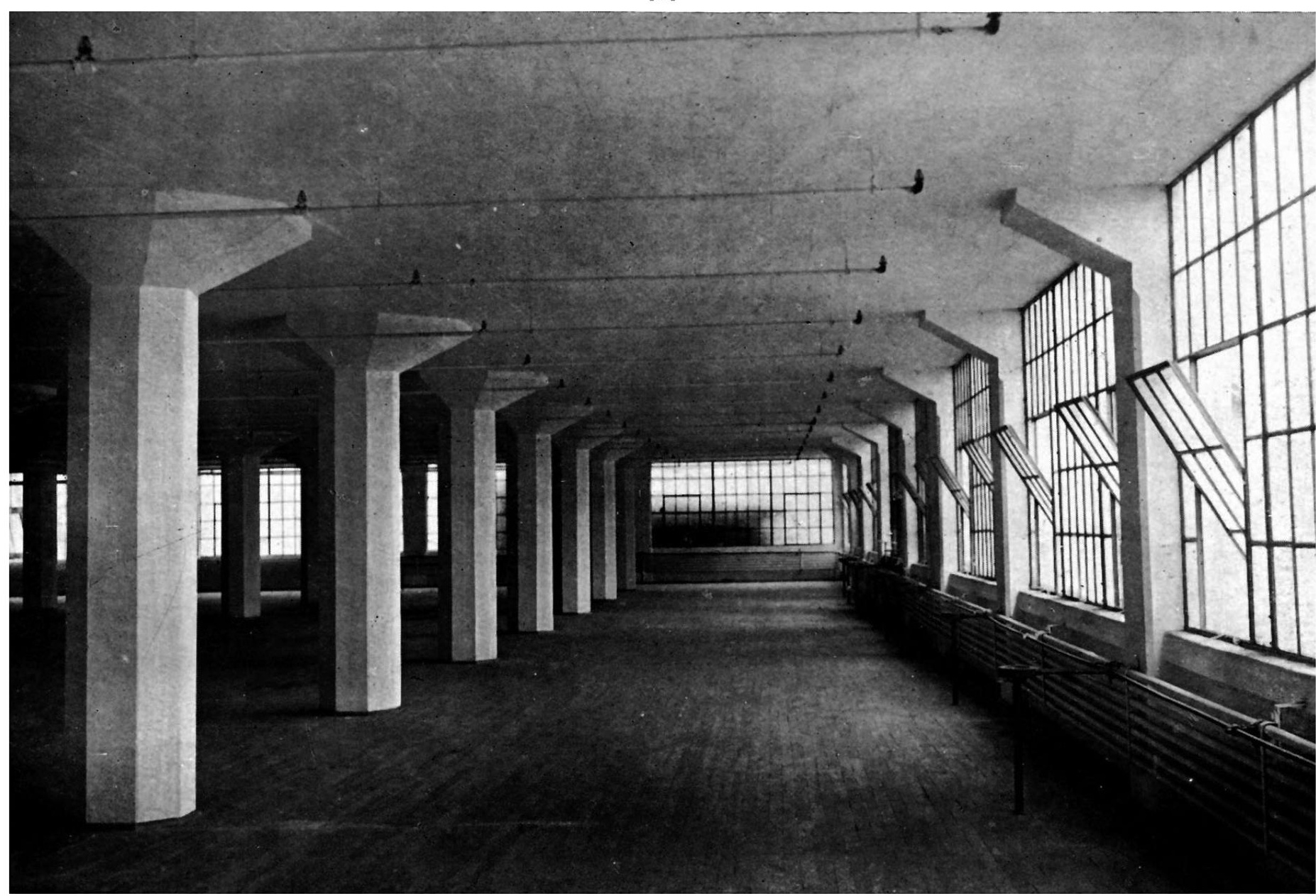

